\title{
PODE O CONHECIMENTO DAR ALGUMA ALEGRIA? UMA INTERPRETAÇÃO DA “MELANCOLIA I", DE ALBRECHT DÜRER, A PARTIR DA "ÉTICA" DE SPINOZA
}

\author{
Marcos Ferreira de Paula* \\ marcosfdepaula@yahoo.fr
}

Para o meu amigo Marcus Vinícius

RESUMO Este artigo busca interpretar a gravura "Melancolia I", do renascentista alemão Albrecht Dürer, segundo o pano de fundo filosófico do pensamento de Spinoza. A ideia central é a de que, nessa gravura, haveria uma intuição artístico-filosófica pela qual Dürer foi levado a associar a tristeza melancólica à ideia de um conhecimento confuso e turvado pela imaginação. Tal intuição se completaria numa outra gravura, criada no mesmo ano, o "São Jerônimo em seu gabinete", na qual a melancolia do "homem de cultura" renascentista desaparece. Tais intuições permitiriam ler as duas gravuras sob a ótica das "teorias" da mente e do conhecimento de Spinoza, para quem o conhecimento está associado à alegria, desde que esteja livre das sombras da imaginação projetadas pelo medo, pelo desejo excessivo, pelas crenças ou pelas superstições.

Palavras-chave Arte, melancolia, conhecimento, alegria, Spinoza, Dürer.

* Professor Adjunto de Filosofia da Universidade Federal de São Paulo (Unifesp). Artigo submetido em 28/12/2013 e aprovado em 26/06/2014. 
ABSTRACT This article seeks to interpret the engraving "Melencolia I" (1514), made by the German Renaissance's painter Albrecht Dürer, according to the philosophical background of Spinoza's thought. The central idea is that, in this picture, there would be an artistic-philosophical intuition by which Dürer associated melancholy to the idea of a confused and muddied knowledge caused by imagination. Another engraving, also created in 1514, completes this intuition: "St. Jerome in his study", in which the melancholy of the Renaissance's "man of culture" disappears. Such insights allow reading the two pictures from the perspective of Spinoza's "theories" of mind and knowledge. He assumes that knowledge is associated with joy, since it is free from the shadows of the imagination projected by fear, excessive desire, beliefs or/and superstitions.

Keywords Art, Melancholy, Knowledge, Joy, Spinoza, Dürer.

I'll change my state with any wretch, /Thou canst from gaol or dunghill fetch; /My pain's past cure, another hell, /I may not in this torment dwell! /Now desperate I hate my life, /Lend me a halter or a knife; /All my griefs to this are jolly, / Naught so damn'd as melancholy

(Robert Burton, "The anatomy of melancholy”) ${ }^{1}$

\section{I}

Quando, no século XVII, o filósofo holandês Baruch de Spinoza (16321677) elaborou um pensamento no qual o conhecimento e a alegria são inseparáveis, estava lutando contra toda uma tradição que, desde o "Problema XXX, 1", atribuído a Aristóteles, buscou sempre associar o "homem de gênio" à "melancolia". ${ }^{2}$ Desde a Antiguidade, a ideia do gênio melancólico aristotélico não deixou de fazer escola. Poetas, filósofos, grandes políticos e

1 "Cada problema me incendeia,/ não sais do lixo ou da cadeia;/ Curo uma dor, vem outro Inferno,/ Não suporto um tormento eterno!/ Desesperado, odeio a vida,/ Em faca ou corda, acho a saída:/ Mas toda dor vira alegria,/ Mais maldita é a Melancolia", na tradução de Guilherme Gontijo Flores para a edição da Editora UFRP. Cf. Burton, 2011, p. 51.

2 Conhecemos a pergunta que abre o "Problema XXX, 1": "Por que razão todos os que foram homens de exceção, no que concerne à filosofia, à ciência do Estado, à poesia ou às artes, são manifestamente melancólicos, e alguns ao ponto de serem tomados por males dos quais a bile negra é a origem, como contam, entre os relatos relativos aos heróis, os que são consagrados a Hércules?”. Diógenes Laércio, em sua "Vida dos filósofos ilustres" (V, 23), atribui esse texto a Aristóteles. Como argumenta Jackie Pigeaud, nem mesmo o fato de Cícero, nas "Tusculanas", ou de Sêneca, no "De Tranqulitate animi", terem citado o texto e atribuído-o a Aristóteles pode ser tomado como prova da autoria do Filósofo. O texto pode ter sido escrito por um discípulo de Aristóteles; Teofrasto, por exemplo. O que é certo é o texto ser de caráter 
artistas serão considerados, inclusive por si mesmos, também melancólicos. No fundo, o que está sempre no horizonte é uma relação, vista como natural ou intrínseca, entre conhecimento e melancolia.

Grandes melancólicos são dados à genialidade (artística, filosófica, poética, literária, política); grands savants são melancólicos. Essa antiga tese terá também sua importância durante toda a Idade Média, embora em sentido negativo. Não por acaso, mais do que a crítica ou questionamento que o saber pudesse trazer à Revelação das Escrituras, os monges medievais temiam antes a accidia (acédia), essa melancolia medieval que, muito pior do que a aristotélica, levava o monge a ser "abandonado por Deus", mas por sua própria culpa, já que ele havia cometido o maior dos pecados, a perda do interesse pela vida, por si mesmo e pelo próprio divino. Finda a Idade Média, contudo, quando o amor ao conhecimento e às artes ressurgirá com todas as forças, a antiga relação entre genialidade e melancolia também será resgatada, novamente em sentido positivo. E, nesse contexto, Marcílio Ficino será sem dúvida o maior e mais conhecido expoente do savant mélancolique.

Numa era de grandes filósofos, artistas e cientistas, o Renascimento será, como afirma Jean Starobinski, a "era de ouro" da melancolia: "Sob a influência de Marsílio Ficino e dos platônicos de Florença", afirma o autor, "a melancoliatemperamento aparece como o apanágio quase exclusivo do poeta, do artista, do grande príncipe, e sobretudo do verdadeiro filósofo" (cf. Starobinski, 2005, p. 571). Este "sobretudo" nos interessa, aqui, porque indica que a melancolia da época estava mais associada ao conhecimento do que propriamente às artes. Pelo menos na concepção de Ficino, que se considerava ele mesmo um melancólico, e afirmava que os melancólicos "mostram às vezes um gênio tão superior que se os diria menos humanos que divinos". ${ }^{3}$ Por isso, se Ficino não deixou de oferecer vários conselhos aos "homens de cultura", não foi com o intuito de curá-los de sua "doença", pois isso significaria eliminar a "causa" da genialidade, mas sim para que tirassem dela o melhor proveito possível (cf. Starobinski, 2005, p. 571). ${ }^{4}$

aristotélico, podendo ser perfeitamente relacionado a algumas passagens de outras obras propriamente de Aristóteles. Cf. Pigeaud, 1998, pp. 51-53 e 81.

3 Neste ponto, Ficino pretende-se seguidor de Demócrito, Platão e Aristóteles. Cf. Ficino, 2005, pp. 580-581.

4 Convém lembrar que há uma diferença sutil entre a melancolia de Ficino e a de Aristóteles. Ficino, ao oferecer uma explicação de como a bílis negra favorece a genialidade do "homem de cultura", seguirá Aristóteles quanto à ideia de "constância na inconstância", mas enfatizará ainda mais o caráter de estabilidade da melancolia no homem excepcional. Para ele, se a bílis pode ser causa de loucuras e manias, ela pode também causar "um humor estável e consistente". Isso porque Ficino considerava a "melancolia natural" nada mais do que "a parte do sangue mais espessa e mais seca", isto é, mais próxima do sólido e do estável. Daí a ideia de se poder tirar bons proveitos da melancolia que, como se vê, está aqui longe de ser considerada uma doença propriamente dita. Cf. Ficino, 2005, p. 581. 
A melancolia renascentista daria por si só um artigo à parte. O que nos interessa é apenas o fato de que Ficino influenciará muitos de seus contemporâneos, e Albrecht Dürer não escapará ao seu raio de influência; sua "Melancolia I", de 1514, foi certamente elaborada num contexto de forte presença das ideias de Ficino, ${ }^{5}$ o qual deixará sua marca também nas gerações posteriores. No século XVII, por exemplo, Robert Burton citará Ficino mais de uma vez em sua monumental "A anatomia da melancolia", de 1621. ${ }^{6}$ Mas se a partir da medicina do século XVIII tem início a inversão dos sinais que qualificam a melancolia, tratando-a agora como doença, tal mudança já se iniciara no século XVII, com a filosofia de Spinoza.

De fato, em sua "Ética", Spinoza não hesita em definir a melancholia como a mais profunda das tristezas: "[...] a Melancolia", escreve o filósofo, "é a Tristeza que, enquanto se refere ao Corpo, consiste em que a potência de agir do Corpo é absolutamente [absolute] diminuída ou coagida [...]" (Spinoza, 2014, Parte IV, proposição 42, demonstração). ${ }^{7}$ Como a alegria fora definida como aumento da potência de agir (seja do corpo, seja da mente), uma absoluta diminuição ou coibição da potência é também uma tristeza profunda. ${ }^{8}$ Eis a nossa questão: se é assim, a melancolia não poderia estar associada à criatividade - artística, filosófica ou outra qualquer - uma vez que, no limite, ela levaria à total incapacidade de agir, de se fazer o que quer que seja, como nos atuais casos de depressão profunda, e a exemplo da personagem Justine, no "Melancholia" do diretor Lars von Trier. Mas, neste caso, como explicar a tese aristotélica, que não deixa de apresentar, a seu favor, muitos exemplos empíricos, como é o caso do próprio Dürer, de Burton e tantos outros? É nesse quadro de questões que gostaríamos de interpretar a gravura de Dürer, a "Melancolia I".

5 Segundo Erwin Panofsky, o contato entre Dürer e Ficino se deu sobretudo por meio da obra de Cornelius Agripa, o "De Occulta Philosohia". Teremos que voltar a esse ponto, mais adiante. Cf. Panofsky, 1945, pp. 168-169.

6 Por exemplo, nesta passagem: "Tal é a embriaguês de que fala Ficino, quando a alma é elevada e arrebatada por um sabor divino do néctar celeste, que os poetas decifraram pelo sacrifício de Dionísio, e neste sentido, para o poeta, insanire lubet [ensandecer apraz], como nos exorta Agostinho, ad ebrietatem quisque paret, sejamos todos loucos e ébrios". Cf. Burton, 2011, p. 139.

7 Utilizamos aqui a tradução coletiva - da qual fizemos parte - realizada pelo Grupo de Estudos Espinosanos, do Depto. de Filosofia da USP, e que será publicada pela Edusp em breve. As passagens da "Ética" que citaremos neste artigo são todas desta tradução.

8 Teremos ocasião de retomar, mais adiante, o enunciado desta proposição, a fim de tentar elucidar um problema que ela traz, e que já podemos adiantar aqui: se a melancolia é a absoluta diminuição da potência, ela é um afeto que não pode ser vivenciado, pois esta absoluta diminuição não é outra coisa senão a morte do corpo e, portanto, da mente. 
Figura 1 - "Melancolia I". Albrecht Dürer, 1514. Gravura.

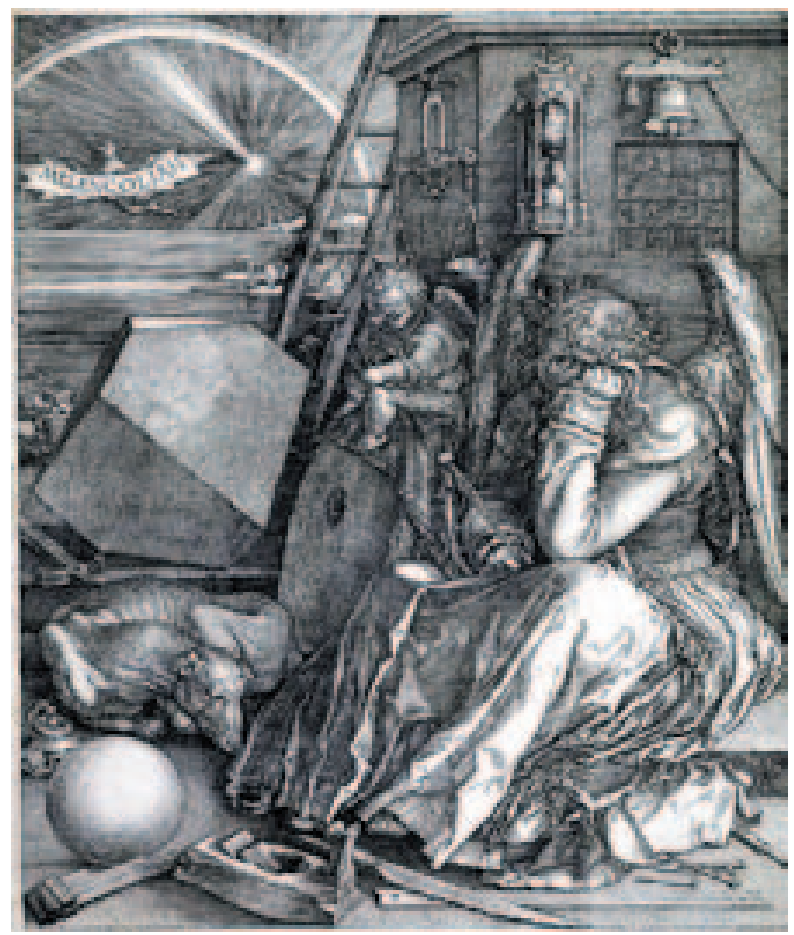

Disponível em http://pt.wikipedia.org/wiki/Melancolia I. Acessado em 7 de junho de 2014.

Na "Melancolia I" (1514), Dürer mostra-nos uma personagem rodeada de objetos que simbolizam a busca do conhecimento. Vemos aí, em destaque, uma personagem alada (um "home-anjo" ou simplesmente um humano que traz consigo atributos divinos, representados pelas asas em suas costas); ela tem em suas mãos um compasso, que remete à geometria, tão importante nos séculos XVI e XVII; mas em seu colo um livro repousa fechado. Estará ela observando uma grande figura sólida e geométrica, um poliedro? A referência às matemáticas, porém, não param por aí: também aparece atrás da personagem alada, na figura do "quadrado mágico", aquele em que os números de 1 a 16 são dispostos de tal modo que a soma de quatro números na vertical, na horizontal ou na transversal é sempre 34. Um pequeno anjo, que aparece na gravura, 
talvez seja a antítese da grande figura alada ou grande anjo: concentrado, ele trabalha sobre seu buril como quem anota algo em um caderno, e não deixa ver nenhum vestígio de tristeza. Atrás deste pequeno anjo nós vemos uma balança, antigo símbolo da justiça e do equilíbrio, assim como uma escada, que ruma ao céu, simbolizando certamente a ascensão neoplatônica da alma pela via da filosofia (filosofar é tornar-se divino) - comentadores da obra consideram essa escada um dos símbolos bíblicos e a chamam "escada de Jacob". Ao fundo da imagem, o que nós vemos é um cometa, uma das poucas fontes de luz em toda a cena. Mas não é talvez por acaso que justamente aí, perto do céu, de onde poderia provir a luz, símbolo antigo do conhecimento e da razão, que Dürer figurou o título da gravura, com a inscrição "Melencolia I" sendo segurada por uma espécie de cão-morcego. Aliás, o cão, nas obras que retratam a melancolia, representa sempre os sentidos (e por extensão a libido, o desejo e os prazeres do corpo); aqui ele aparece também aos pés da personagem alada, adormecido, quieto (os sentidos estão portanto adormecidos, controlados); e, perto dele, encontramos, por fim, certos objetos de carpintaria, representando as artes manuais, mas com os quais se poderia construir, talvez, instrumentos úteis ao próprio trabalho de conhecimento...

Há certamente muitos outros elementos pictóricos, nesta obra que é rica em detalhes (a ampulheta, o sino, a pinça, os pregos, as réguas e serrotes e outros instrumentos de corte; uma esfera lisa próxima ao cão adormecido etc.). Mas quase todos eles parecem remeter o expectador ao tema da busca pelo conhecimento e às artes manuais. Diante de todos esses elementos, no entanto, a grande personagem alada, à primeira vista, parece dar pouca importância, como se interrogasse a si mesma sobre a utilidade de tudo aquilo que está à sua disposição. Na imagem, o que permite uma tal leitura é certamente o rosto da personagem que, apoiado em sua mão esquerda, não deixa de ser o gesto simbólico do savant fatigué que se pergunta para quê, afinal, serve tudo aquilo. $\mathrm{O}$ motivo da mão suportando o rosto do melancólico aparece em diversas obras, como, por exemplo, em "O melancólico" de Jacob De Gheyn (1565-1629), no "São Jerônimo" (em torno de 1550) de Martino Rota, segundo Michiel Coxie, na "Melancolia" de Hans Sebald Beham (1539); ou ainda em "O Poeta" (1630), água-forte de Jusepe de Ribera. Mas por que a tristeza, a melancolia, contida no gesto da personagem alada, diante das portas abertas pelas possibilidades do conhecimento? Estaríamos aqui diante de um "sábio anjo" que, como Eclesiastes, após tentar conhecer tudo o que há sob o sol, considera que "tudo é apenas vanidade", "que uma grande sabedoria é acompanhada de uma grande indignação", e "que quanto mais se tem 
conhecimento, mas se tem dor" (“Eclisiastes”, I, 18)? Será este o tipo de sábio melancólico aqui figurado?

Esta é uma maneira de ver a gravura de Dürer. A própria criação de "Melancolia I" por Dürer, neste caso, seria sintomática do "homem de cultura" da época desiludido com o trabalho intelectual. Como escreve G. Minois:

Quando em 1514 Albrecht Dürer realiza a gravura Melancolia I, ele tem trinta e oito anos e perdeu suas ilusões. Pelos trinta anos ele acreditava ainda na possibilidade de atingir a beleza absoluta, universal, graças às matemáticas. Mas pouco a pouco ele desliza para um sombrio ceticismo, agravado por visões e sonhos [...]. (Cf. Minois, 2003, p. 141)

De certa maneira, a "Melancolia I" é o próprio Dürer tentando curar sua dor. Maria Bolaños, analisando o tema da melancolia na arte de vanguarda dos inícios do século XX, faz uma comparação entre a "Melancolia I" e o "Herói com uma asa", de Paul Klee, na qual ela afirma que "[...] ambos compartem o fundo da mesma doença: a do desassossego produzido pelos conhecimentos incompletos, a fatal impossibilidade de alcançar o absoluto, o desencorajamento ante os próprios limites" (cf. Bolaños, 1996, p. 13).

Uma maneira de ver. Mas essas interpretações podem ser contrapostas às interpretações mais cuidadosas de Erwin Panofsky e de Francis A. Yates. Em "The Life and Art of Albrecht Dürer", Panofsky argumenta que o contato entre Dürer e o melancólico Ficino não se deu imediatamente por intermédio do "De amore" ou de outra obra, mas por meio da obra de Cornelius Agrippa, o "De Occulta Philosophia", publicado apenas em 1531, mas cuja versão manuscrita de 1509 e 1510 já circulava entre os humanistas alemães (cf. Panofsky, 1945, pp. 168-169). Leitor de Agrippa, que por sua vez teve Ficino como principal referência, Dürer teria representado em "Melancolia I" apenas a primeira etapa de um processo de "inspiração Saturniana" da alma rumo ao conhecimento de todos os mistérios do Universo. Essa primeira etapa seria marcada pela "imaginação" (imaginatio), enquanto na segunda a "razão" (ratio) é que estaria no centro do processo de ascensão da alma, que só se completaria ao atingir a terceira etapa, o estágio do "intelecto [mind] "intuitivo" (mens). Para Agrippa, uma mesma inspiração de Saturno, um mesmo furor melancholicus, poderia proporcionar três tipos de gênios: naqueles em que a imaginação é mais forte, o furor produziria "maravilhosos artistas ou craftsmen como os pintores e os arquitetos"; naqueles em que a razão predomina, grandes cientistas; e, por fim,

9 "Saturnian inspiration", no original. Como se sabe, Saturno é o planeta que representa a melancolia. Cf. Panofsky, 1945, p. 169. 
naqueles dotados de intuição, o furor produziria o que poderíamos chamar de "grandes místicos", porque capazes de conhecer os mistérios divinos do Universo. Para Panofsky, "Melancolia I", então, representando a primeira etapa, figuraria uma personagem que exprime tristeza, decepção e frustração, uma vez que ela se encontra no campo da imaginação que pode criar e construir muitas coisas, "mas ela não tem acesso ao mundo metafísico". ${ }^{10}$

Yates segue essa mesma linha interpretativa, em "The Occult Philosophy in the Elizabethan Age", mas a partir dela oferece uma interpretação um pouco diferente. A autora considera que na "Melancolia I" a personagem alada não representaria o "gênio melancólico" que se encontra frustrado diante dos impasses do conhecimento ou da sombra do ceticismo, por estar dominado por uma imaginação que o impede de acessar o plano intuitivo do conhecimento metafísico. A gravura representaria antes a primeira etapa de uma melancolia inspirada que conserva três graus de ascensão pelo conhecimento mágico ou oculto: a imaginação, a razão e o intelecto; e a cada um desses níveis correspondem, respectivamente, os demônios que inspiram as artes manuais, o conhecimento das coisas naturais e humanas, e os segredos divinos. O melancólico inspirado estaria protegido contra tais demônios, porque praticante de uma "magia branca ascética", da qual, na gravura, os elementos indicativos seriam as asas, o anjo e a escada que leva ao céu. A gravura de Dürer representaria a primeira etapa dessa "magia branca", marcada pela imaginação e pelas artes manuais, donde todos os instrumentos e ferramentas que figuram na gravura. O título, "Melancolia I", seria indicativo de que estamos nessa primeira etapa, enquanto o "São Jerônimo em seu gabinete", obra composta igualmente em 1514, representaria a terceira etapa, marcada pela presença do intelecto intuitivo que acessa os segredos divinos, e seria portanto uma espécie de "Melancolia III" (cf. Yates, 2010, p. 69). Assim, a personagem da "Melancolia I" não representaria "o gênio trágico e infeliz" (donde a mão apoiando o rosto), mas antes a imaginação inspirada do gênio melancólico dotado da visão inspirada que se realiza em três níveis (cf. Yates, 2010, pp. 65-70). Seu gesto melancólico - a mão que segura o rosto - não exprimiria propriamente uma tristeza, mas a atitude de quem se encontra num "transe visionário" (visionary trance) que, se deixa a personagem inativa, não é por colocá-la num estado depressivo, mas sim por proporcionar-lhe uma “intensa visão interior" (intense inner vision), própria desse "primeiro estágio de inspiração" (cf. Yates, 2010, p. 66). 
Figura 2 - "São Jerônimo em seu estúdio”. Albrecht Dürer. Litogravura, 1514.

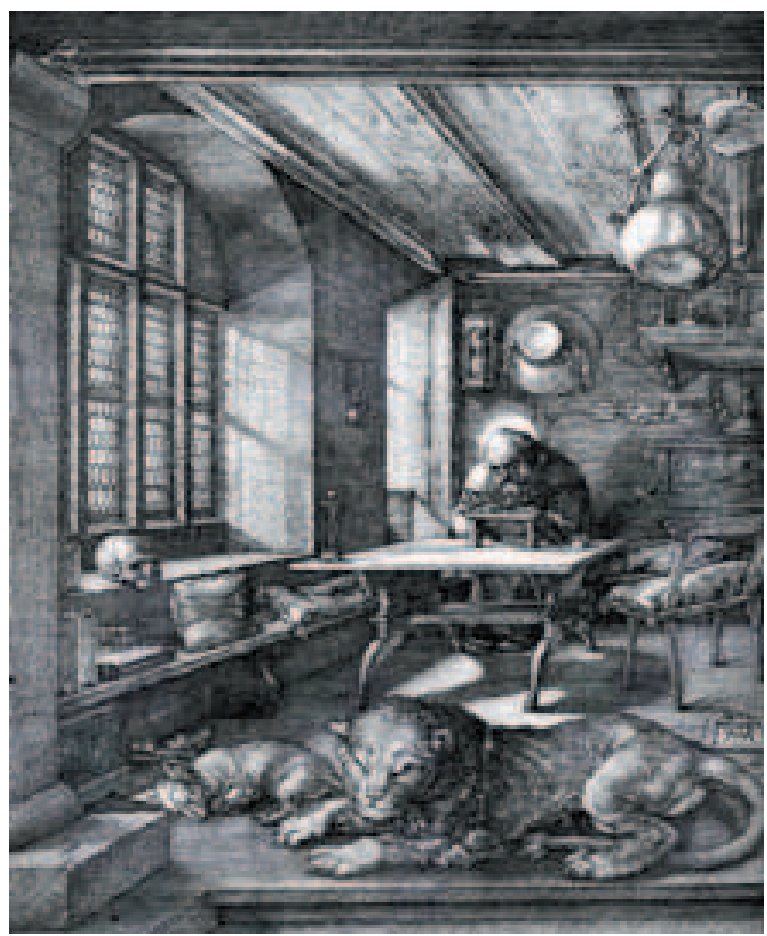

Disponível em en.wikipedia.org/wiki/Saint_Jerome_in_His_Study_(Dürer). Acessado em 8 de junho de $20 \overline{1} 4$.

No entanto, melancolia inspirada é ainda melancolia. Mesmo que se considere "Melancolia I" como o primeiro passo de um processo de conhecimento rumo ao "intelecto intuitivo" iluminado, conhecedor dos mistérios, é preciso admitir que a tristeza paira sobre o "anjo" como uma sombra, um negrume, e que, assim, bloqueia a entrada da luz do conhecimento. Daí não só o gesto da personagem alada, a mão que segura o rosto, e sua inatividade, mas também o próprio título da obra. Mas, quanto ao título, por que esse "I" após o "Melancolia"? Haveria, então, o "II" (obra que teria se perdido), e o "III", que seria talvez o próprio "São Jerônimo em seu estúdio"? É o que pensa Yates. Um título, porém, às vezes diz mais, no fundo, do que o que enuncia na superfície. Se o primeiro "estágio da visão inspirada" de Agrippa é o da "imaginação inspirada", e se Dürer, ao representar esse estágio, dá-lhe o nome de "Melencolia", é porque a imaginação deve ter algo a ver com a tristeza. Isso explicaria por que o "São Jerônimo" não recebeu o nome 
de "Melancolia III": nada, aí, exprime tristeza; os elementos que simbolizam o conhecimento estão ordenados, bem dispostos, a cabeça de São Jerônimo está divinamente iluminada; a luz do sol, aliás, perpassando os vidros das janelas, ilumina quase todo o gabinete; e, sobretudo, Jerônimo encontra-se num estado de concentração em sua leitura, num estado de atividade intelectual que não vem acompanhado do clássico gesto melancólico do "sábio" que segura seu rosto com uma das mãos. Neste aspecto, estaríamos de acordo com a descrição de Panofsky, que, ao contrapor as duas obras, considera que Dürer "transformou a célula de S. Jerônimo num lugar de beatitude encantada" (cf. Panofsky, 1945, p. 155).

Ousaríamos afirmar, a partir desta interpretação de Panofsky, que Dürer transforma também a própria "filosofia oculta" de Agrippa: Yates está certa, o "São Jerônimo" representaria o terceiro estágio da "visão inspirada", mas se em Agrippa os três estágios são momentos de uma mesma "melancolia inspirada", em Dürer a melancolia desaparece no terceiro momento, restando apenas o conhecimento, o uso do intelecto, a atividade no lugar da inatividade, a alegria no lugar da tristeza. E, aqui, não desejamos sugerir nenhuma ligação com a biografia de Dürer; desconhecemos o quanto essas duas obras estão conectadas com a vida pessoal do artista. O que nos interessa é antes a presença do que chamaríamos de "intuição filosófica" que teria ocorrido a Dürer, provavelmente a partir de suas leituras da obra de Agrippa: a saber, essa conexão entre imaginatio e tristeza, em "Melancolia I", e alegria (ou serenidade) e conhecimento, em "São Jerônimo em seu estúdio". Gostaríamos de explicar essa possível intuição nos termos da "teoria do conhecimento" de Spinoza, a fim de oferecer nossa interpretação da gravura de Dürer.

\section{III}

Em sua "Ética demonstrada à maneira dos geômetras", particularmente na segunda parte da obra, intitulada "De Natura et Origine Mentis" ("Sobre a natureza e origem da mente"), Spinoza nos oferece uma filosofia da mente que tem implicações sobre uma "teoria do conhecimento". Não podemos aqui, por razões de tempo e espaço, expor tal filosofia em seus pormenores. Destaquemos apenas que ela está ancorada numa complexa metafísica da imanência, a partir da qual Spinoza deduz a origem e a essência da mente, considerando-a como expressão imanente, "certa e determinada", da atividade do intelecto infinito de "Deus", a Substância absolutamente infinita da qual nosso corpo e nossa mente seriam expressões modais ("modos") das atividades eternas e infinitas de certos atributos (no caso, a Extensão e o Pensamento) da Substância única. 
O que nos interessa especificamente é que Spinoza também trabalha com a divisão da mente em três dimensões, a saber, a "Imaginação" (imaginatio), que ele chama de "primeiro gênero de conhecimento", a "Razão" (ratio), "segundo gênero de conhecimento" e a "ciência intuitiva" (scientia intuitiva), o mais alto grau do conhecimento, pela qual o homem é capaz de conhecer a essência singular de seu corpo como expressão modal imanente da atividade igualmente singular da Natureza inteira. Contudo, ao contrário das tradições aristotélicas e platônicas, que influenciaram toda a posteridade até o século XVII, passando pelos renascentistas, imaginação, razão e ciência intuitiva não são faculdades separadas da mente, mas três dimensões ou estruturas cognitivas inseparáveis de uma mesma mente que é ela própria uma atividade pensante inseparável do seu corpo, porque sua essência é ser ideia do seu corpo existente em ato: "O objeto da idéia que constitui a Mente humana", escreve Spinoza, "é o Corpo, ou seja, um modo certo da Extensão, existente em ato, e nada outro" (cf. Spinoza, 2014, Parte II, proposição 13). ${ }^{11}$

Essa definição da mente tem várias implicações cognitivas e éticas. No campo cognitivo, implica que a mente conhece a si, seu corpo e as coisas exteriores sempre a partir de seu corpo, pois ela é, antes de tudo, uma ideia de seu corpo, e uma ideia que produz novas ideias. Isso faz com que o ponto de partida do trabalho da mente seja a imaginação, isto é, uma ideia da imagem produzida em seu corpo em sua relação consigo mesmo e com exterior. Esta relação, por sua vez, está envolvida em todo e qualquer esforço (conatus) de perseveração na existência, o qual, segundo Spinoza, constitui a essência de todos os seres. ${ }^{12}$ Nesse esforço, a potência de existir (isto é, de ser, agir e pensar, no caso dos humanos) pode ser aumentada ou diminuída: a dor e a fome, num organismo complexo, diminuem-na; a sensação prazerosa e o alimento aumentam-na. A esse aumento e a essa diminuição da potência de existir, Spinoza dá o nome de alegria e tristeza, respectivamente. ${ }^{13}$ Por isso o

11 Utilizamos aqui a tradução coletiva - da qual fizemos parte - realizada pelo Grupo de Estudos Spinozanos, do Depto. de Filosofia da USP, e que será publicada pela Edusp em breve.

12 Cf. Spinoza, 2014, Parte III, proposição 7: "O esforço pelo qual cada coisa se esforça para perseverar em seu ser não é nada além da essência atual da própria coisa”. Evidentemente, nas coisas que chamamos de "inanimada", esse esforço seria inercial ou "passivo", enquanto nos organismos vivos, capazes de agir e reagir ao ambiente, ele é antes "ativo". Spinoza, contudo, não coloca as coisas nesses termos: a diferença entre os seres, se consideramos apenas sua essência ontológica, isto é, a perseveração no próprio ser, seria apenas de grau (não, evidentemente, de essência); o que os diferencia, ontologicamente, é a modalidade de perseveração: uma pedra não foge, como o faz um pernilongo, diante da mão que ameaça seu ser; e, no entanto, ela permanecerá existindo indefinidamente, se nenhuma causa externa vier destruí-la. É que, para Spinoza, "Nenhuma coisa pode ser destruída senão por uma causa externa". Cf. Spinoza, 2014, Parte III, proposição 4.

13 As definições de alegria e tristeza enunciam: "A Alegria é a passagem do homem de uma perfeição menor a uma maior"; "A Tristeza é a passagem do homem de uma perfeição maior a uma menor"; Cf. Spinoza, 
exercício da mente tem consequência também no campo ético, já que, para Spinoza, desejo (que é a própria essência humana ${ }^{14}$ ), alegria e tristeza estão na base da criação de valores morais e estéticos. ${ }^{15}$

Eis por que, para Spinoza, a melancolia é uma tristeza profunda, na qual o indivíduo está, no limite, completamente incapacitado de agir e pensar. No escólio da proposição 11 da Parte III da "Ética", Spinoza define a melancholia como o afeto pelo qual "todas as partes são igualmente [pariter] afetadas" de tristeza, e nessa medida ela é o afeto oposto ao de hilaritas (hilaridade ou contentamento), pelo qual todas as partes do corpo são igualmente afetadas de alegria. ${ }^{16}$ Todavia, na demonstração da proposição 42 da Parte IV, Spinoza introduz uma modificação importante no conceito de melancolia. Relembremos a definição do filósofo:

Já a Melancolia (cuja def. também se vê no mesmo esc. da prop. 11 da parte III) é a Tristeza que, enquanto se refere ao Corpo, consiste em que a potência de agir do Corpo é absolutamente diminuída ou coagida [absolute minuitur vel coercetur].

Essa modificação permite-nos compreender a melancolia como um afeto de tristeza que, atingindo igualmente todas as partes do corpo, diminui absolutamente sua potência de agir, e consequentemente a potência de pensar da mente que dele é a ideia. Tal diminuição, sendo absoluta, faz da melancolia um afeto que pode ser definido, mas não vivenciado em sua plenitude: pois, no limite, a melancolia é a própria morte, e na morte já não há afetos, que são variações da potência de existir. Em "La stratégie du conatus", Laurent Bove não hesita em afirmar que, na ética de Spinoza, a "Melancolia é de fato o adversário principal", porque, sob ela, "o conatus pode ser totalmente vencido por neutralização, paralisia, inversão de suas forças de vida em forças de morte" (cf. Bove, 1996, p. 121). A melancolia é a dinâmica afetiva que, no limite, leva à morte - uma dynamique du suicide, como afirma Bove (1996, p. 120) - mas que só se realizaria totalmente na morte. Nesse ponto, contudo, o corpo próprio do indivíduo existente não comporta qualquer dinâmica afetiva.

2014, Parte III, "Definições dos Afetos" II e III. Como, na Parte II, Spinoza enunciara na Definição 6 que "Por realidade e perfeição entendo o mesmo", entende-se que a passagem a uma maior ou menor perfeição é a passagem a um maior ou menor "grau" de realidade, o que, na ontologia do necessário de Spinoza significa maior ou menor capacidade de produzir efeitos, ou seja, uma maior ou menor potência de agir.

14 Cf. Spinoza, 2014, Parte III, "Definições dos Afetos" I: "O Desejo é a própria essência do homem enquanto é concebida determinada a fazer (agir) algo por uma dada afecção sua qualquer".

15 Ver o Apêndice da Parte I da "Ética".

16 Cf. Spinoza, 2014, Parte III, proposição 11, escólio: “[...] o afeto de Alegria simultaneamente relacionado à Mente e ao Corpo, chamo Carícia ou Hilaridade; o de Tristeza, por sua vez, Dor ou Melancolia. Contudo, cumpre notar que a Carícia e a Dor são referidas ao homem quando uma das partes dele é afetada mais do que as outras; já a Hilaridade e a Melancolia, quando todas as partes são igualmente afetadas". 
Em Spinoza, a melancolia totalmente realizada seria como a morte em Epicuro: é um nada para o indivíduo, pois enquanto ele vive, ela não está, e quando ela está, ele já não vive. ${ }^{17}$ Entendida, porém, como "dinâmica suicida" - isto é, como processo afetivo que leva tendencialmente à morte - a melancolia é compreensível tanto conceitualmente quanto empiricamente (lembremos aqui os casos contemporâneos de depressão profunda).

Nossa questão é saber por que, em Spinoza, o conhecimento pode ser um antídoto contra a melancolia, já que, como sugerimos acima, à atividade de conhecimento está sempre associado um afeto de alegria. É preciso então mostrar a conexão necessária entre conhecimento e alegria, que Spinoza propõe em sua "Ética". Sem entrar nos meandros da Parte II, precisamos revisitar, minimamente, as noções de conhecimento imaginativo, racional e intuitivo, em Spinoza. Mas para isso temos que recorrer às noções básicas da estrutura metafísica elaboradas no "De Deo", a Parte I da "Ética".

Spinoza demonstra, no "De Deo", que a Natureza ou Deus é Causa sui, causa de si, e que ela é uma Substância absolutamente infinita, cuja essência é constituída de infinitos atributos infinitos. ${ }^{18} \mathrm{Um}$ atributo, em Spinoza, é uma "essência atuosa" (actuosa essentia). ${ }^{19}$ Todo atributo é assim produção necessária. A própria Substância é, portanto, autoprodução necessária de si mesma e, nessa medida, ela é produção necessária de infinitos modos de infinitas maneiras, que são expressão certa e determinada de cada um de seus atributos (cf. Spinoza, 2014, Parte I, proposição 16). Modos são modulações ou, se quisermos, particularizações de uma mesma Substância. A partir dessa metafísica, Spinoza pode demonstrar, na Parte II, que a mente é um modo do atributo Pensamento e que sua essência é ser ideia de um corpo existente em ato, o qual é modo do atributo Extensão. Como o atributo Pensamento é uma essência atuosa infinita, ele produz infinitas ideias de tudo o que há, isto é, de todas as essências, de tudo o que é e existe. Dentre essas coisas, estão as próprias ideias. Logo, o atributo pensamento é ele mesmo potência reflexiva: produz não só ideias das coisas como também ideias dessas ideais. A ideia

17 Como escreve Epicuro na Carta a Meneceu: "Acostuma-te à ideia de que a morte para nós não é nada, visto que todo bem e todo mal residem nas sensações, e a morte é justamente a privação de sensações"; e, em outra passagem: "Então, o mais terrível de todos os males, a morte, não significa nada para nós, justamente porque, quando estamos vivos, é a morte que não está presente; ao contrário, quando a morte está presente, nós é que não estamos”. Cf. Epicuro, 2002, pp. 27-29.

18 Cf. Spinoza, 2014, Parte I, definições 1 (causa de si) e 6 (Deus).

19 Cf. Spinoza, 2014, Parte II, proposição 2, escólio: "Em seguida, mostramos, na prop. 34 da parte I, a potência de Deus nada ser além da essência atuosa de Deus; e por isso nos é tão impossível conceber que Deus não age quanto conceber que Deus não é". 
imediata que o atributo produz da Natureza inteira é o que Spinoza chama de intelecto infinito, o qual é um modo infinito imediato do Pensamento.

Uma dentre as ideias das coisas produzidas pelo intelecto infinito da Substância é a ideia do corpo humano. A essa ideia Spinoza dá o nome de mente. Não podemos entrar aqui nos detalhes da teoria spinoziana da mente, mas cabe afirmar que a mente humana é essencialmente a ideia de um corpo existente em ato. Ela é uma ideia complexa porque é a ideia de um corpo igualmente complexo. Expressão certa e determinada da atividade do atributo pensamento, a mente é potência reflexiva: ela não apenas é uma ideia de seu corpo existente em ato, mas também uma ideia dessa ideia, idea ideae. Ela é portanto reflexividade. Quando Spinoza fala em autômato espiritual (automa spirituale) (Espinosa, 2001, § 85, p. 52), seu leitor compreende o quanto sua teoria da mente escapa a todas as filosofias da representação e do sujeito pensante: as ideias da mente não são essencialmente representações, mas ações, e ações de uma atividade necessária.

$\mathrm{O}$ fato de ser potência reflexiva implica que, quando a mente conhece algo, ela sabe que conhece. Se esse conhecimento favorece seu ser, ela e seu corpo experimentam essa ideia (sentem-na) como um aumento da potência de existir, ou seja, como alegria. Tal conhecimento pode ser meramente imaginativo; por exemplo, a simples lembrança de que há alimentos prontos na geladeira, se estou com fome: conhecimento imaginativo, pois a memória não nos oferece a certeza intelectual de que os alimentos estão ainda lá. Não importa: o que importa é que ele é experimentado como alegria (assim como, inversamente, ao abrir a geladeira e não encontrar lá os alimentos que eu desejava, experimento esta ideia como tristeza). Aqui, a produção de ideias na mente é determinada externamente por nossa relação com os corpos exteriores. Neste campo, as ideias produzidas são os próprios afetos passivos; e elas são ideias inadequadas, porque somos apenas a causa parcial delas. Os afetos passivos - seja de desejo, alegria, tristeza etc. - são ideias do que se passa no corpo quando este é exteriormente determinado a agir (passividade, paixões). O campo da imaginação envolve exterioridade e passividade, e as ideias aí são confusas e inadequadas.

Ocorre que há um tipo de alegria inerente à produção de ideias verdadeiras e de conhecimento adequado. Ao produzir suas ideias, a mente pode ser internamente determinada por sua própria potência. Neste campo, as ideias produzidas são adequadas. Na definição 3 da Parte II da "Ética", Spinoza afirma que uma ideia é um "conceito da mente, que a mente forma por ser coisa pensante". Esta ideia é produzida pela mente enquanto ideia do corpo, e não porque ideia do que se passa no corpo (esta última é propriamente um 
afeto do ânimo, expressão psíquica do que nele se passa: paixão e imaginação, como vimos). O axioma 3 da Parte II enuncia: "Modos de pensar como amor, desejo, ou quaisquer outros que sejam designados pelo nome de afeto do ânimo, não se dão caso no mesmo indivíduo não se dê a ideia da coisa amada, desejada etc. Mas a ideia pode dar-se ainda que não se dê nenhum outro modo de pensar". Assim, na ordem do intelecto, as ideias produzidas na mente seguem a ordem própria da mente enquanto coisa pensante. Spinoza afirma que a ordem das ideias adequadas é tão necessária quanto as ideias inadequadas e confusas ( $E$ III, 36), mas enquanto estas dependem dos encontros fortuitos dos corpos, as ideias adequadas seguem uma ordem necessária que é intrínseca à própria mente. Seguindo uma tal ordem, a mente produz autonomamente suas ideias, isto é, ela é causa adequada das ideias, cuja produção depende apenas da mente. O que é uma ideia adequada? É, afirma Spinoza, precisamente a ideia que, "enquanto considerada em si mesma, sem relação com o objeto, tem todas as propriedades ou denominações intrínsecas de uma ideia verdadeira" ( $E$ II, def. 4). Ou seja, a ideia verdadeira não é verdadeira porque corresponde ao objeto fora dela: tal correspondência é apenas uma denominação ou propriedade extrínseca da ideia verdadeira (como quando afirmo que há um alimento na geladeira e ele realmente está lá); ela é verdadeira porque traz em si mesma o signo de sua verdade (quando afirmo que o movimento de uma semirreta, que tem uma de suas extremidades fixa, produz um círculo, tal ideia é verdadeira em si mesma, sem que este círculo precise existir fora da mente).

Precisamente essa produção interna da mente é inseparável de um afeto de alegria. Como a mente é potência reflexiva, ao ter uma ideia verdadeira e adequada, ela não pode deixar de saber que a tem; mas cada ideia verdadeira que a potência de pensar da mente produz é um acréscimo, um aumento de sua própria capacidade de pensar. E a mente, que é reflexividade, não pode deixar de experimentar esse acréscimo, esse aumento: ou seja, ela não pode deixar de se alegrar com esse conhecimento verdadeiro. Mas é preciso ainda dizer que o esforço da mente em conceber ideias verdadeiras e adequadas não advém do acaso: trata-se ele mesmo de um esforço do indivíduo que, por diversas causas, foi determinado a buscar o melhor, o mais útil. "Por bem", escreve Spinoza no escólio da proposição 36 da Parte IV, "entenderei isso que sabemos certamente nos ser útil". Se temos uma ideia adequada do que nos é útil, à alegria envolvida na produção em si da ideia adequada acrescenta-se a utilidade que decorre, no plano da ação, dessa mesma ideia: o mais útil, aqui, é aumento da potência de pensar da mente e, simultaneamente, aumento da potência de agir do corpo. Alegria plena. 
Justamente esse tipo de conhecimento, com o sentimento da certeza que ele envolve, não está contido no conhecimento imaginativo. Por isso, mesmo que na imaginação esteja envolvida uma alegria (e isso ocorre frequentemente), tal alegria não pode ser duradoura, como o é a alegria envolvida na ideia verdadeira e adequada. Pois todo conhecimento adequado, para Spinoza, comporta a dimensão da eternidade (a certeza de que, em um espaço euclidiano, a soma dos ângulos internos do triângulo é necessariamente $180^{\circ}$, vale para qualquer época e qualquer lugar). Eis por que a ciência intuitiva, sendo o maior grau de conhecimento que a mente pode atingir, é por isso mesmo a maior alegria que podemos conquistar. Spinoza afirma que, na ciência intuitiva, alcançamos a Felicidade, Beatitude ou Liberdade, porque somos capazes de compreender que a essência singular de nosso corpo pertence à essência imanente da Natureza inteira (Deus ou a Substância), tanto em sua dimensão extensa quanto em sua dimensão pensante.

\section{IV}

Ainda que não tenhamos desenvolvido aqui todos os passos demonstrativos da teoria da mente e do conhecimento em Spinoza, não é difícil admitirmos, após o que foi dito acima, que o conhecimento adequado envolve necessariamente alegria. Mas se é assim, por que a figura alada da "Melancolia I" encontra-se em estado de inatividade e de certo abatimento? Por que está melancólica, como sugere o título da obra, quando está cercada de elementos que remetem não só ao conhecimento, mas ao conhecimento certo, exato, verdadeiro, isto é, o conhecimento matemático e geométrico?

Segundo Yates, como vimos acima, a gravura representaria um primeiro estágio da visão inspirada do "De occulta philosophia" de Agrippa, estágio no qual a imaginação é o elemento central. Mas mesmo em Spinoza a imaginação não é sinônimo de tristeza. Pelo contrário, é precisamente no campo da imaginação que operamos quando vivemos nossas paixões alegres; apenas elas não podem ser alegrias duradouras, porque derivam de nossa relação com objetos perecíveis e transitórios (como, para citar os maiores exemplos, o dinheiro, o sexo, o poder, as honrarias e a fama). A imaginação, em si mesma, não é uma impotência, e Spinoza chega a afirmar que, quando a mente percebe 
que está imaginando, a imaginação é neste caso uma potência. ${ }^{20}$ Bons exemplos disso são os grandes escritores: Flaubert, Machado de Assis ou Proust, p. ex., narram todo um universo de paixões em que vivem suas personagens; mas não necessariamente vivenciam estas mesmas paixões os autores da narrativa: imaginam-nas, mas sabem que imaginam e, por isso, não são dominados pela própria imaginação.

Exemplos como estes permitem-nos compreender melhor a ideia, lançada acima, de que imaginação, razão e ciência intuitiva constituem dimensões ou estruturas cognitivas inseparáveis da mente humana. Esse é um tema difícil, em Spinoza, que exigiria desdobramentos teóricos que estão muito além do escopo deste artigo. Mas não podemos deixar de oferecer algumas palavras sobre o assunto, até porque ele afeta a interpretação que ofereceremos mais adiante sobre o lugar do conhecimento na "Melancolia I" de Dürer.

O início da trajetória do desenvolvimento psicofísico do indivíduo humano é marcado pela presença quase total da imaginação: com um corpo já complexo, mas ainda extremamente dependente do exterior, a criança é movida pela imaginação, quase nada pela razão, e ainda menos pela ciência intuitiva. Spinoza abre o conjunto de definições da Parte II da "Ética" - que, como dissemos, trata da mente humana - com uma definição de corpo, e não de mente, cuja definição sequer se encontra entre as setes definições iniciais do "De mentis". Não sendo o objeto de um conhecimento a priori, e sim aquilo que deve ser demonstrado, a definição de mente não está no ponto de partida, mas apresenta-se apenas ao fim do percurso que culmina na proposição 13, cujo escólio, não por acaso, desenvolve toda uma "pequena física" dos corpos, resultando, por sua vez, na definição de indivíduo. Todo esse desenvolvimento dedutivo do "De Mentis", que vai das definições até o escólio da proposição 13, permite-nos afirmar que a ideia de um corpo é tanto mais complexa quanto mais complexo é esse corpo. O corpo infantil da criança está ainda imerso numa passividade, cuja marca é a quase completa dependência do mundo exterior. O corpo do "sábio", ao contrário, é desenvolvido ao ponto de ele poder afetar e ser afetado de muitas maneiras simultaneamente. No primeiro caso, predomina a imaginação; no segundo a razão e a ciência intuitiva. Mas o adulto conserva uma vantagem que a criança não tem: nele, as três estruturas cognitivas - imaginação, razão e intuição - estão presentes, e ele será tanto

20 Cf. Spinoza, 2014, Parte II, proposição 17, escólio: "Pois se a Mente, enquanto imagina coisas não existentes como presentes a si, simultaneamente soubesse que tais coisas não existem verdadeiramente, decerto atribuiria esta potência de imaginar à virtude de sua natureza, e não ao vício; sobretudo se esta faculdade de imaginar dependesse de sua só natureza, isto é (pela def. 7 da parte I), se esta faculdade de imaginar da mente fosse livre". Consideramos que é dessa liberdade que goza o grande artista. 
mais "sábio" quanto mais puder fazer uso da razão e da ciência intuitiva. Na figura do "sábio", não desaparecem a razão e a imaginação. O "sábio" é aquele que faz delas um uso mais apropriado ao seu desejo de buscar e gozar de uma verdadeira felicidade e liberdade.

Em resumo, se na criança predomina a imaginação sobre a razão (não havendo nela, talvez, qualquer vestígio de "ciência intuitiva"), no "sábio" a ciência intuitiva (ou intuição racional) prepondera sobre a razão e a imaginação. Corpos diferentes, mentes diferentes. Eis por que se pode afirmar sem contradição o fato de haver na mente dimensões ou estruturas cognitivas distintas, copresentes, mas que não se confundem. A presença e o predomínio de cada uma delas vai depender da estrutura e complexidade do corpo de que a mente é a ideia. Também por aí se poderia explicar que, nos grandes artistas, a imaginação não é desvario, como no sonho ou nos loucos, mas antes é auxiliar de uma razão estética que permite criar obras dotadas de um sentido que pode ser lido ou visto por outros. É sem dúvida o caso de Dürer. Mas como interpretar a presença do conhecimento e sua relação com a imaginação, na "Melancolia I"? A resposta a essa pergunta constituirá a parte final do nosso artigo.

\section{V}

Nós sabemos o quanto as artes e o conhecimento foram prezados durante o Renascimento. Ficino, como vimos acima, considerava que "gênios" melancólicos poderiam ser escritores e filósofos, não tanto artistas; já Cornelius Agrippa considerava que artistas, escritores, cientistas ou filósofos poderiam ser todos inspirados pelo mesmo furor melancholicus, embora o mais sábio seria aquele que alcança o terceiro estágio do "intelecto intuitivo" e desvenda os mistérios divinos. Em ambos os casos, portanto, o mais importante é um certo conhecimento metafísico. No Renascimento, todavia, tudo se passa como se mil portais estivessem abertos ao conhecimento do homem e do Universo. Nesse período de grandes recuperações, de grandes resgates dos legados das culturas greco-romanas, diversas formas de conhecimento pululam, mas não podem deixar de se misturar com o legado das tradições místicas alquimistas, além do da tradição judaico-cristã medieval, sobretudo o neoplatonismo e o misticismo judaico da cabala. O resultado é uma espécie de confusão, de embaraço, em que as grandes promessas que emergem pela revalorização do conhecimento e da cultura humanistas se acompanham de ceticismo, desconfiança e até decepções. O Renascimento, com efeito, é esse momento da história da cultura ocidental em que o desenvolvimento do conhecimento 
é promissor, mas também confuso: a astronomia mistura-se à astrologia, a matemática à numerologia, a filosofia à teologia, a química à alquimia. Um desenvolvimento e, contudo, o conhecimento não consegue apontar para uma direção certa e segura, não consegue mostrar sua própria utilidade, nem cumprir suas promessas, mostrando assim a impotência daquele que imaginava poder tirar do trabalho de conhecimento mais do que ele realmente podia proporcionar, já que contaminado pelos anseios da imaginação.

O melancólico de Dürer é uma personagem que representa bem esse momento. As possibilidades abertas pelas redescobertas humanistas e pela revalorização do conhecimento laico não deixam de estar acompanhadas, ainda, da imaginação teológica da tradição judaico-cristã e da imaginação mágicoalquimista. Eis por que o melancólico de Dürer precisa estar protegido contra seus próprios demônios por outros seres sobrenaturais (representados pelo anjo, as asas, a escada de Jacó que ruma ao céu): ele não consegue "proteger-se" pela força de sua própria inteligência ou genialidade. Significa que, sem as proteções mágicas, ele poderia desesperar-se do conhecimento e de sua genialidade, caindo em profundo abatimento (o que não é aqui o caso, e nesse ponto concordamos, de certa forma, com a interpretação de Yates). Assim, a gravura de Dürer pode ser vista como representativa daquela confusão de conhecimentos que acabamos de assinalar, com as artes, a ciência e a filosofia misturadas com o ocultismo, a magia e a religião. Diante dessa indefinição do próprio campo e alcance do conhecimento, a personagem alada não deposita no conhecimento, nas artes ou na filosofia, por si mesmos, a confiança capaz de livrá-la da melancolia. Dessa maneira, é o lugar do saber que permanece precário. $\mathrm{O}$ abatimento (embora não profundo) e a inatividade (embora não total) da personagem alada estão ligados ao papel frágil que tal conhecimento representa para o gênio melancólico.

A "Melancolia I", assim, nos oferece a imagem da imaginação diante das possibilidades infinitas do conhecimento. Tudo se passa como se, sob a imaginação, a personagem alada não soubesse o que fazer com tantos recursos à disposição, caindo em certo abatimento, que se exprime em seu gesto, típico dos melancólicos, e em sua inatividade diante dos recursos à sua frente. Mas a gravura de Dürer diz mais. Misturando figuras que remetem ao conhecimento e à razão com figuras que remetem à magia e à imaginação, ela representa, juntos, num mesmo espaço pictórico, os dois primeiros momentos da "visão 
inspirada" de Agrippa, a imaginatio e a ratio, mostrando que mesmo a razão é impotente se, como diria Spinoza, o intelecto não for reformado, corrigido ou emendado. ${ }^{21}$ Significa que a razão é impotente, em termos spinozianos, quando não se dirige corretamente ao "objeto" que importa conhecer antes de tudo: a causa prima imanente que, causa de todas as coisas, é também causa imanente de nosso corpo-mente. Mas sobretudo, para Spinoza, a "emenda do intelecto" passa pela utilização de uma razão que busca o conhecimento verdadeiro sem crenças, teologias ou superstições (que são formas de imaginação): ela o faz apenas mediante sua própria potência interna. Sem isso, ela não pode levar àquele estágio da "ciência intuitiva" que proporciona a suma alegria, isto é, a beatitude, a felicidade ou a liberdade.

A "intuição artística" (e, de certo modo, "spinoziana") de Dürer estaria, portanto, em figurar, na "Melancolia I", essa impotência da razão que se vê ainda sob as garras ou sob a sombra da imaginação. É esta a causa da melancolia, não o conhecimento em si. ${ }^{22}$ Mas que a "Melancolia I" represente em termos pictóricos a ideia de que a razão renascentista encontra-se ainda estorvada pela imaginação dos conhecimentos herméticos, ficinianos, cabalísticos etc., devese antes a essa "intuição", mais do que a uma ideia conscientemente elaborada e figurada na tela. Da mesma maneira, não foi, nos parece, uma ideia consciente que guiou Dürer na elaboração de "São Jerônimo em seu gabinete". Dürer

21 Referimo-nos, aqui, ao famoso "Tractatus de Intellectus Emendatione", o "Tratado da Emenda do Intelecto". No Brasil, Lívio Teixeira, por exemplo, traduziu a obra dando-lhe o título de "Tratado da reforma da inteligência". Cf. Espinosa, 2001.

22 Nossa interpretação, até certo ponto, vai ao encontro da leitura de Henrique Piccinato Xavier, feita em dissertação de mestrado, intitulada "Eternidade sob a duração das palavras: Simultaneidade, Geometria e Infinito na Ética de Spinoza". Trata-se de leitura muito interessante, que de certo modo se contrapõe à interpretação de Yates, que teria enfatizado a relação entre Dürer e a "filosofia oculta" renascentista de Agrippa, esquecendo-se de que o próprio Dürer fora seguidor de Lutero e, por isso, era um crítico dos ocultismos e misticismos da época. Ele mesmo um geômetra, Dürer prezava antes as modalidades de conhecimento matemático, em geral, e geométrico, em particular. Contudo, a partir de uma igualmente interessante interpretação do poliedro que aparece na figura, Xavier considera que o "sólido geométrico de faces irregulares" representa o antigo problema da "quadratura do círculo", problema insolúvel, segundo Dürer, para quem seria vã toda tentativa de se chegar à unidade da esfera perfeita a partir de figuras quadradas. Ora, a esfera perfeita, em sua unidade, é símbolo antigo do Divino. Assim, o que Dürer estaria nos mostrando, nessa gravura, seria a impossibilidade do conhecimento matemáticogeométrico de alcançar Deus em sua unidade perfeita, donde a melancolia inscrita nessas modalidades de conhecimento - e o "l" que aparece no título da obra não seria, como quer Yates, a representação de uma primeira fase da ascensão rumo ao conhecimento místico inspirado por Saturno, mas aquela da "unidade" inatingível. Para Xavier, em suma, a gravura de Dürer figuraria a ideia de que geometria e matemática, operando com medidas e números, inscrevem-se ainda no campo da imaginação, e por isso não são capazes de nos oferecer um conceito verdadeiro do Infinito, algo que será feito apenas no século seguinte, sobretudo com Spinoza e sua "Ética demostrada à maneira dos geômetras". Cf. Xavier, 2008, pp. 34-43. Nossa única divergência em relação a tal leitura é que, para nós, na gravura de Dürer não haveria uma crítica aos conhecimentos matemáticos e geométricos em si mesmos, dada sua incapacidade de nos elevar ao Infinito, mas exprimiria antes o problema de eles estarem misturados à "imaginação", representada pelos elementos das tradições místicas e ocultista do período renascentista. 
não é um Spinoza avant la lettre. É um artista, não um filósofo, e um artista de seu tempo. Adepto dos círculos luteranos de uma Alemanha renascentista porém protestante, ele é portador de um humanismo que não poderia ser o mesmo de um Vermeer (1632-1675), por exemplo. Que se compare, aqui, o "estúdio" de "O geógrafo" (1668) ou de "O astrônomo" (1668), óleos sobre telas que parecem dispensar quaisquer implicações religiosas na construção do cenário do estudioso. Não era o caso em "São Jerônimo em seu estúdio". E, no entanto, acreditamos que aquela "intuição filosófica" que levou Dürer a associar a mistura entre imaginação e conhecimento à condição melancólica daquele que tem todas as "asas" para ir ao céu, mas se vê impotente para tanto, tal "intuição" completa-se justamente na outra obra composta no mesmo ano de 1514, "São Jerônimo", que representaria não o terceiro estágio da "visão inspirada" de Agrippa, mas antes a condição do homem de saber marcado pela presença e o uso do "intelecto intuitivo", condição na qual a melancolia já não tem lugar, apenas a serenidade proporcionada pelo trabalho da mente no desvendamento de questões que são de ordem metafísica. Se, como afirmou Panofsky (1945, p. 156), Dürer costumava presentear seus amigos oferecendo-lhes uma cópia da "Melancolia I" junto com uma cópia de "São Jerônimo", talvez seja o caso de lermos as mensagens dessas duas gravuras sob a perspectiva da relação que uma parece manter com a outra. $\mathrm{Na}$ primeira, a imaginação é a sombra que paira sobre as possibilidades infinitas da experiência intelectual, causando a melancolia; na segunda, a melancolia desaparece porque, tranquilo em seu estúdio, o estudioso volta seu intelecto para aquilo que, segundo Spinoza, importa conhecer antes de qualquer outro "objeto": a estrutura metafísica e ontológica do Infinito positivo, do Universo. Mas o leitor, aqui, pode ainda objetar que São Jerônimo foi antes teólogo que filósofo, sendo por isso marcado pela imaginação das Escrituras, e não pelo exercício livre da potência da razão. Diremos que, contudo, o "Jerônimo" de Dürer é o Jerônimo que emerge da visão de um humanista, não de um teólogo; e que, precisamente por isso, em vez de se abater diante dos insondáveis mistérios revelados pela imaginação dos profetas ou pelas fantasias dos ocultistas, ele antes se alegra com o próprio trabalho sereno e paciente de seu intelecto.

\section{Referências}

ARISTÓTELES. "O homem de gênio e a melancolia: o Problema XXX, 1". Rio de Janeiro: Lacerda Editores, 1998.

BOLAÑOS, M. “Pasages de la melancolía”. Espanha: Junta de Castilla y Léon, 1996. 
BOVE, L. "La stratégie du conatus: affirmation et résistance chez Spinoza". Paris: Vrin, 1996.

BURTON, R. "A anatomia da melancolia”. Curitiba: UFPR, 2011.

EPICURO. "Carta sobre a felicidade (a Meneceu)". São Paulo: Unesp, 2002.

ESPINOSA, B. "Tratado da reforma da inteligência”. Tradução de Lívio Teixeira. São Paulo: Martins Fontes, 2001.

FICINO, M. "De vita triplici”. In: Y. Hersant. Mélancolies: de l'Antiquité au XXe siècle. Paris: Éditions Robert Laffont, 2005.

HERSANT, Y. "Mélancolies": de l'Antiquité au XXe siècle. Paris: Éditions Robert Laffont, 2005.

MINOIS, G. "Histoire du mal de vivre: de la mélancolie à la dépression". Paris: Éditions de La Martinière, 2003.

PANOFSKY, E. "The Life and Art of Albrecht Dürer". New Jersey: Princeton University Press, 1945.

PIGEAUD, J. "Apresentação". In: Aristóteles. O homem de gênio e a melancolia: o Problema XXX, 1. Rio de Janeiro: Lacerda Editores, 1998.

SPINOZA, B. "Ética”. São Paulo: Edusp, 2014, no prelo.

STAROBINSKI, J. "Histoire du traitement de la mélancolie, des origines à 1900". In: Y. Hersant. Mélancolies: de l'Antiquité au XXe siècle. Paris: Éditions Robert Laffont, 2005.

XAVIER, H. P. "Eternidade sob a duração das palavras: simultaneidade, geometria e infinito na Ética de Spinoza". 2008. 157 f. Dissertação (Mestrado em Filosofia) Departamento de Filosofia, FFLCH-USP, São Paulo, 2008.

YATES, F. "The Occult Philosophy in the Elizabethan Age". London/NY: Routledge, 2010. 